\title{
Egressos dos Programas de Pós- Graduação em ciência da informação: por onde andam os doutores?
}

Daisy Pires Noronha

Professora Doutora do Dept. de Biblioteconomia e Documentação. Pesquisadora do Centro de Pesquisa de Produção Científica-NPC da Escola de Comunicações e Artes da USP

Dinah Aguiar Población

Professora Doutora do Dept. de Biblioteconomia e Documentação. Pesquisadora do Centro de Pesquisa de Produção Científica-NPC da Escola de Comunicações e Artes da USP

Leonardo da Silva de Assis

Bolsista de Iniciação Científica do NPC/ECA/USP

Tatiana Hyodo

Mestranda do PPGCI - ECA/USP . Colaboradora do NPC/ECA/USP

Apresenta a formação dos doutores egressos dos programas brasileiros de Pós-graduação em Ciência da Informação, no período de 2000-2005, e sua inserção no mercado acadêmico após a sua titulação. Os dados foram coletados dos currículos disponíveis na Plataforma Lattes $(\mathrm{CNPq})$, identificando-se o atual vínculo desses nos cursos de graduação, especialização e pós-graduação. Constatou-se um crescimento do envolvimento dos doutores em atividades de ensino, com destaque à graduação.

Palavras-chave: Pós-Graduação; Ciência da Informação; Teses de Doutorado; Docência. 


\section{Egress of graduate programs in information science: where the doctors}

The article provides a reflection about the profiles of doctors from the Brazilian Information Science graduate programs from 2000 to 2005, identifying their current link to undergraduate, specialization and graduate courses. The data were obtained from CVs at the "Plataforma Lattes" managed by CNPq. A growth in the involvement of doctors in education activities, mainly in undergraduate courses, was verified.

Keywords: Graduate course; Information Science; Doctor Thesis.

Recebido em 29.03.2009 Aceito em 24.07.2009

\section{Introdução}

Os cursos de pós-graduação, nas últimas três décadas, vêm se impondo como um intenso processo de expansão na formação e manutenção de massa crítica da comunidade científica brasileira, principalmente em nível de doutorado. A partir desses cursos, torna-se evidente o aumento da contribuição no fortalecimento das diferentes áreas do conhecimento, com a atuação do egresso, mestre e doutor, no ensino superior, tanto na graduação como na pós-graduação. Segundo consta, os cursos de graduação deveriam ter um terço do corpo docente, pelo menos, com titulação acadêmica de mestrado ou doutorado (SAVIANI, 1988, citado por POBLACION, 1993). Mas, mesmo considerando-se as deficiências ainda encontradas nos processos educacionais brasileiros, a titulação dos docentes tem propiciado consideráveis avanços voltados ao completo sistema de graduação e pósgraduação acadêmica (GUIMARÃES, 2002).

Enfocando a área de Ciência da Informação (CI) no Brasil, o desempenho dos profissionais carece de profunda reflexão a partir dos Programas de capacitação de recursos humanos. O resgate histórico da pesquisa e da pós-graduação na área da $\mathrm{CI}$, ao longo dos 35 anos de existência, apresentado por diferentes abordagens (BARRETO, 1992; POBLACIÓN, 1993; MIRANDA, 1998; MUELLER; MIRANDA; SUAIDEN, 2000; POBLACION e NORONHA, 2003; POBLACION; PRAZERES e OLIVEIRA, 2006), oferece subsídios adequados para identificar, no primeiro quinquênio deste século, o perfil e o desempenho dos doutores egressos dos Programas de Pós-Graduação em Ciência da Informação 
(PPGsCI) já consolidados na área, e o atual vínculo que eles mantêm com o mercado de trabalho acadêmico. Com isso, esses cursos, priorizando a qualificação e o aprimoramento dos recursos humanos para o ensino e pesquisa, têm condições para enfrentar aos desafios propostos para o engrandecimento da área, além de contribuir para satisfazer a demanda do mercado de trabalho.

Os primeiros Programas de pós-graduação na área da CI, iniciados em nível de mestrado em 1972 (IBICT) e doutorado a partir de 1980 (USP), somente atingem a consolidação de massa crítica a partir de 1999, quando todo o corpo docente dos PPGsCI, níveis mestrado e doutorado, passou a ser constituído exclusivamente por doutores (com exceção dos cursos da USP e da UnB que, desde a data de instalação, mantiveram exclusivamente doutores em seu quadro) (POBLACION, 1993). No início dos cursos, nos anos 1970, devido à escassez de professores titulados em CI, o corpo docente foi constituído por professores e renomados especialistas convidados, provenientes de diferentes áreas. A natureza multidisciplinar da ciência da informação reforça esse quadro, o que se reflete nas diferentes graduações dos pós-graduandos em ciência da informação. Este foi o resultado encontrado em pesquisa realizada por Poblacion, Prazeres e Oliveira (2006), onde se verificou que, dos 119 docentes vinculados aos 9 PPGsCI existentes em 2006 (mestrado e doutorado), 67 (56,3\%) eram doutores em Ciência da Informação graduados nessa mesma área (16 titulados no exterior e 51 no Brasil), enquanto 52 eram provenientes de outras áreas (museologia, administração, computação, engenharia, sociologia, filosofia, química, história, lingüística, geografia, educação, comunicação, saúde pública, artes, economia e letras) (NORONHA; FUJINO, 2006). Esse perfil diversificado da formação profissional e das atividades de pesquisa da área vem se firmando após o crescimento dos cursos de doutorado. Assim, procura-se obter respostas a frequentes questionamentos relacionados ao perfil dos profissionais que demandam o doutorado da área, como: saber quem são os doutores titulados no país em $\mathrm{CI}$; qual a formação dos profissionais que demandam os PPGs da área; o que faziam antes e o que passam a fazer após a titulação; e, enfim, como o título de doutor obtido nos PPGsCI vem contribuindo para o engrandecimento e o fortalecimento da massa crítica da área.

Solucionar este questionamento é uma meta de pesquisa de ampla especulação que mostra, com o presente estudo, um recorte do universo de dúvidas existentes sobre o assunto. Respostas a uma parte desses quesitos, como identificar a área de formação (graduação) dos egressos doutores em CI, sua atuação, como profissional ou docente, antes e após a titulação, e identificar aqueles que, após o título, atuam nos próprios PPGsCI, na formação de outros mestres e doutores, constituem o objetivo do presente estudo. 


\section{População de estudo}

O corpus da pesquisa foi constituído por doutores egressos no período de 2000 a 2005, titulados nos quatro Programas de PósGraduação em Ciência da Informação vinculados às instituições USP, IBICT (junto às universidades UFRJ e UFF), UnB e UFMG, que mantinham, além do mestrado, o curso de doutorado. A identificação dos mesmos deu-se mediante consulta aos sites dos Programas e foi completada com dados do perfil (área de formação e atuação profissional) extraídos do Currículo da Plataforma Lattes do CNPq, tendo sido realizada no período de maio a junho de 2007.

\section{Resultados}

No referido período do estudo (2000-2005), conforme a TAB. 1, foram identificados 122 doutores egressos dos quatro Programas de PósGraduação em Ciência da Informação: IBICT (47); UFMG (31); USP (27) e UnB (17).

TABELA 1 Número de doutores egressos dos Programas de Pós-

Graduação em Ciência da Informação (2000-2005)

\begin{tabular}{c|c|c|c|c|c|c|c|c|c}
\hline $\begin{array}{c}\text { PPGs-Cl (ano } \\
\text { início } \\
\text { doutorado) }\end{array}$ & $\mathbf{2 0 0 0}$ & $\mathbf{2 0 0 1}$ & $\mathbf{2 0 0 2}$ & Total & $\mathbf{2 0 0 3}$ & $\mathbf{2 0 0 4}$ & $\mathbf{2 0 0 5}$ & Total & $\begin{array}{c}\text { Total } \\
\text { geral }\end{array}$ \\
\hline $\begin{array}{c}\text { USP } \\
(\mathbf{1 9 8 0 )}\end{array}$ & 3 & 5 & 3 & 11 & 3 & 11 & 2 & 16 & 27 \\
\hline $\begin{array}{c}\text { IBICT } \\
(\mathbf{1 9 9 2 )}\end{array}$ & 4 & 6 & 5 & 15 & 9 & 11 & 12 & 32 & 47 \\
\hline $\begin{array}{c}\text { UnB } \\
(\mathbf{1 9 9 2 )}\end{array}$ & 2 & 5 & 0 & 7 & 6 & 2 & 2 & 10 & 17 \\
\hline $\begin{array}{c}\text { UFMG } \\
(\mathbf{1 9 9 7 )}\end{array}$ & 3 & 1 & 6 & 10 & 4 & 5 & 12 & 21 & 31 \\
\hline Total & 12 & 17 & 14 & 43 & 22 & 29 & 28 & 79 & 122 \\
\hline
\end{tabular}

Fonte: dados da pesquisa.

Ao analisar o número total de egressos (TAB. 1), destaca-se, no período analisado, o IBICT, responsável pela titulação de $38,5 \%$ dos doutores, onde, no último triênio (2003-2005), o número de doutores egressos (32) supera o total do período de seis anos dos demais Programas. O mais recente dos Programas de doutorado credenciados até 2005 (UFMG, iniciado em 1997) vem se destacando com um crescimento da titulação de doutores na área. O total de egressos (122), para uma área tida como emergente, pode ser considerado representativo na geração de profissionais com o título de doutor, com conseqüente engrandecimento da pesquisa da CI. 
TABELA 2 Disponibilidade dos currículos na Plataforma Lattes dos doutores titulados pelos PPGsCI (2000-2005)

\begin{tabular}{c|c|c|c|c|c}
\hline Situação & IBICT & UFMG & USP & UnB & TOTAL \\
\hline Doutores egressos (2000-2005) & 47 & 31 & 27 & 17 & 122 \\
\hline $\begin{array}{c}\text { Currículos não disponíveis no } \\
\text { Lattes }\end{array}$ & 7 & 3 & 4 & 4 & 18 \\
\hline Currículos analisados & 40 & 28 & 23 & 13 & 104 \\
\hline
\end{tabular}

Fonte: dados da pesquisa.

Para a análise do perfil dos egressos, foram considerados 104 doutores, cujos currículos estavam disponíveis na plataforma Lattes/CNPq na época da coleta. (TAB. 2). O fato de $15 \%$ dos doutores não disponibilizarem seus currículos nessa plataforma pode estar relacionado à não obrigatoriedade desse preenchimento na época, ou, talvez, ao atraso na atualização dos mesmos. Vale lembrar que o preenchimento e a atualização dos currículos dos alunos, pesquisadores e docentes, nessa plataforma, é uma das condições básicas para a avaliação Capes dos Programas de pós-graduação.

\subsection{Formação (graduação) dos egressos doutores}

TABELA 3 Áreas de formação (graduação) dos doutores egressos dos PPGsCI (200-2005)

\begin{tabular}{c|c|c|c|c|c}
\hline Área de Formação - Graduação & USP & IBICT & UNB & UFMG & Total \\
\hline \hline Biblioteconomia & 6 & 8 & 2 & 6 & 22 \\
\hline Comunicação Social & & 2 & 1 & 3 & 6 \\
\hline História & 4 & 2 & & & 6 \\
\hline Ciências Econômicas & & 3 & & 2 & 5 \\
\hline Letras & 1 & 2 & 1 & 1 & 5 \\
\hline Ciências Sociais & 2 & 1 & & 1 & 4 \\
\hline Engenharia Elétrica & & & & 3 & 3 \\
\hline Jornalismo & 1 & 2 & & & 3 \\
\hline Museologia & & 3 & & & 3 \\
\hline Administração & & & 1 & 1 & 2 \\
\hline Ciência da Computação & 1 & & & 1 & 2 \\
\hline Engenharia Civil & & & & 2 & 2 \\
\hline Medicina & & 2 & & & 2 \\
\hline Processamento de Dados & 1 & & 1 & & 2 \\
\hline Arqueologia & & 1 & & & 1 \\
\hline Arquitetura e Urbanismo & & & & 1 & 1 \\
\hline Arquivologia & & 1 & & & 1 \\
\hline
\end{tabular}




\begin{tabular}{|c|c|c|c|c|c|}
\hline Área de Formação - Graduação & USP & IBICT & UNB & UFMG & Total \\
\hline Bacharel em Escultura & & 1 & & & 1 \\
\hline Ciências Biológicas & & 1 & & & 1 \\
\hline Desenho Industrial & 1 & & & & 1 \\
\hline Economia & & & & 1 & 1 \\
\hline Engenharia de Sistemas & & & 1 & & 1 \\
\hline Engenharia Cartográfica & & & 1 & & 1 \\
\hline Engenharia de Computação & & & 1 & & 1 \\
\hline Engenharia Naval & & 1 & & & 1 \\
\hline Engenharia Química & & & & 1 & 1 \\
\hline Farmácia e Bioquímica & & 1 & & & 1 \\
\hline Geologia & 1 & & & & 1 \\
\hline Intendência da Marinha & & & 1 & & 1 \\
\hline Química & 1 & & & & 1 \\
\hline Arquitetura e Urbanismo / Jornalismo & & 1 & & & 1 \\
\hline Biblioteconomia / Jornalismo & 1 & & & & 1 \\
\hline Biblioteconomia / História & & & 1 & & 1 \\
\hline Comunicação Social / Jornalismo & & & 1 & & 1 \\
\hline Desenho Industrial / Comunicação Visual & & 1 & & & 1 \\
\hline Biblioteconomia / Educação Física & 1 & & & & 1 \\
\hline Comunicação Social / Educação Física & & & & 1 & 1 \\
\hline $\begin{array}{c}\text { Engenharia Elétrica / Engenharia } \\
\text { Mecânica }\end{array}$ & & & & 1 & 1 \\
\hline Biblioteconomia / Letras vernáculas & & 1 & & & 1 \\
\hline Medicina / Letras & & 1 & & & 1 \\
\hline Medicina / Filosofia & & & & 1 & 1 \\
\hline Museologia / Comunicação Social & & 1 & & & 1 \\
\hline Biblioteconomia / Filosofia / Teologia & & & 1 & & 1 \\
\hline $\begin{array}{c}\text { Engenharia / Intendência da Marinha / } \\
\text { História }\end{array}$ & & 1 & & & 1 \\
\hline Não Consta & 2 & 3 & & 2 & 7 \\
\hline Total & 23 & 40 & 13 & 28 & 104 \\
\hline
\end{tabular}

Fonte: Dados da pesquisa.

Os doutores egressos dos PPGsCI possuem a graduação em 33 diferentes áreas identificadas nos currículos, sendo que 14 dos egressos têm graduação em mais de uma especialidade. Os profissionais que mais buscaram sua titulação no doutorado em CI, como era esperado, são formados em Biblioteconomia (24\%) e, destes, 5 também possuem outra formação (jornalismo, história, educação física, filosofia/teologia e letras). Além desses graduados em Biblioteconomia, observa-se o predomínio de profissionais de outras especialidades das áreas das ciências sociais / humanas $(50 \%)$, como Comunicação Social, História, Letras, Ciências Econômicas, Ciências Sociais e Jornalismo. Os $20 \%$ dos egressos com formação nas áreas exatas estão representados, principalmente, pelas especialidades das Engenharias (elétrica, civil, mecânica, naval entre outras) e da Ciência da Computação. As áreas biológicas completam o 
quadro (6\%), com maior representatividade para profissionais da Medicina.

Estes resultados vêm ao encontro de um trabalho anteriormente realizado por Población e Noronha (2003), onde se tornou evidente a multidisciplinaridade da CI, pela composição do corpo docente dos PPGsCI, níveis mestrado e doutorado. Posteriormente, o estudo realizado por Santos (2008) mostrou também uma grande variedade de áreas em relação aos cursos de graduação dos mestres e doutores egressos do Programa de Pós-Graduação em Ciência da Informação da UFMG (19922005), com maior porcentagem para os graduados em biblioteconomia.

\subsection{Atuação dos doutores egressos}

A atuação dos doutores egressos, tanto na docência como na profissão (antes e após sua titulação), é mostrada nos GRÁF. 1 e 2.

Assim, pelo GRÁF. 1, no período anterior à titulação, 67 doutores (64,4\%) dedicavam-se às atividades docentes em cursos de graduação, especialização e pós-graduação. Dentre eles, 2 acumulavam cargos na docência e como profissionais liberais. Os demais (34) realizavam atividades profissionais junto a empresas públicas e privadas. Este quesito não foi identificado nos currículos de 3 egressos.

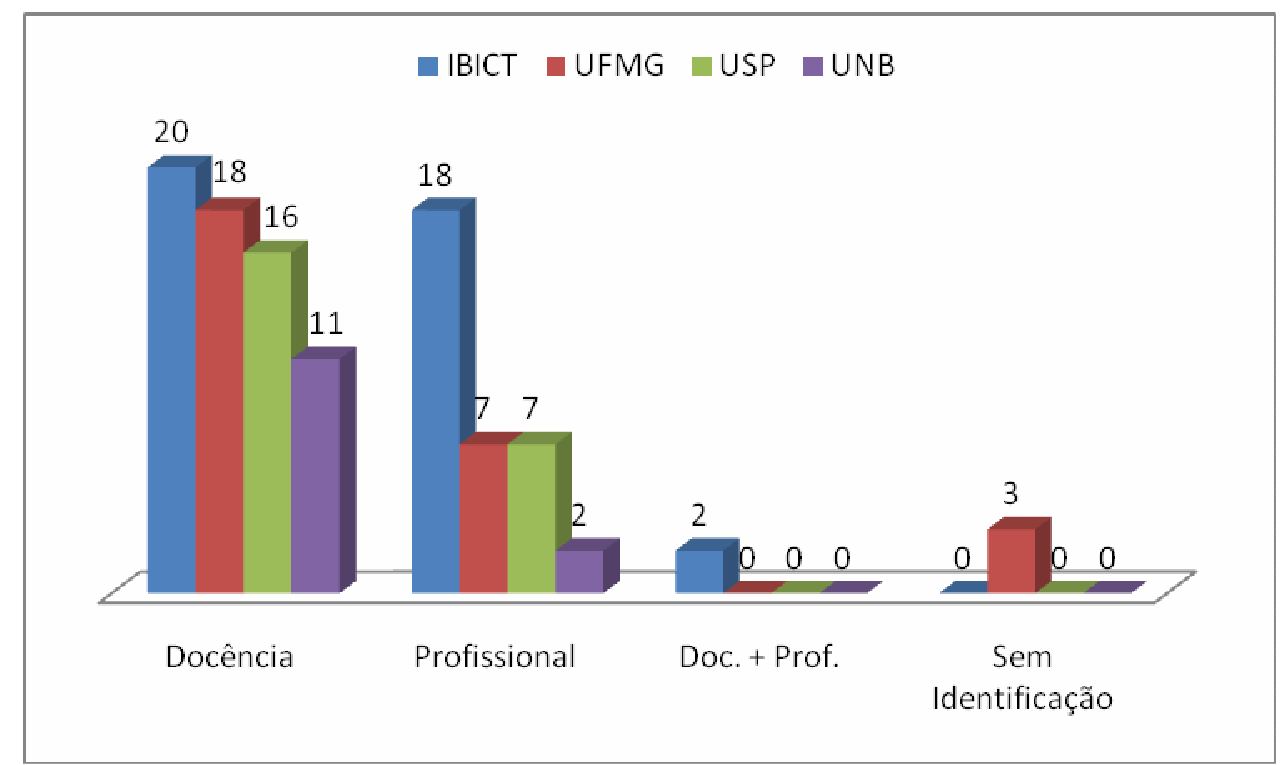

GRÁFICO 1 - Vínculos de atuação dos egressos ANTES do doutorado

Fonte: Dados da pesquisa.

O GRÁF. 2 mostra o vínculo de atuação dos egressos após o doutorado e, como era o esperado, verifica-se um aumento da atividade docente (única ou em conjunto com a atividade profissional). Assim, passam de $67(64,4 \%)$ para $80(76,9 \%)$ os egressos que se dedicam à docência como atividade exclusiva ou não. A pesquisa de Santos (2008) também mostrou uma "maior concentração dos sujeitos após a titulação 
no cargo/função de professor de nível superior". Vale destacar também que houve um aumento no número de egressos que passaram a acumular a docência com outras atividades profissionais após a obtenção do título de doutor (de 2 para 19), com uma pequena queda na atividade exclusiva de docência (de 65 para 61). É possível que o fato do egresso exercer outras atividades profissionais, além da docência, esteja relacionado ao regime de trabalho na academia, que permite o acúmulo de cargos. Os baixos salários das atividades docentes, principalmente nas instituições públicas, que detêm a maioria dos egressos, também podem contribuir para essa dispersão no mercado de trabalho. Por outro lado, este resultado vem mostrar que a pós-graduação estrito senso, além do preparo ao ensino e pesquisa, vem tambem contribuindo para a complementação/atualização do profissional, para seu bom desempenho nas atividades que exerce.

A pós-graduação em CI vem cumprindo sua missão, como está demonstrado em um estudo coordenado por Velloso (2004) sobre o destino profissional de mestres e doutores titulados no Brasil em diversas áreas, onde conluiu-se que "a formação recebida na pós-graduação parece preencher bem as expectativas e demandas das profissões acadêmicas"( $p$. 517).

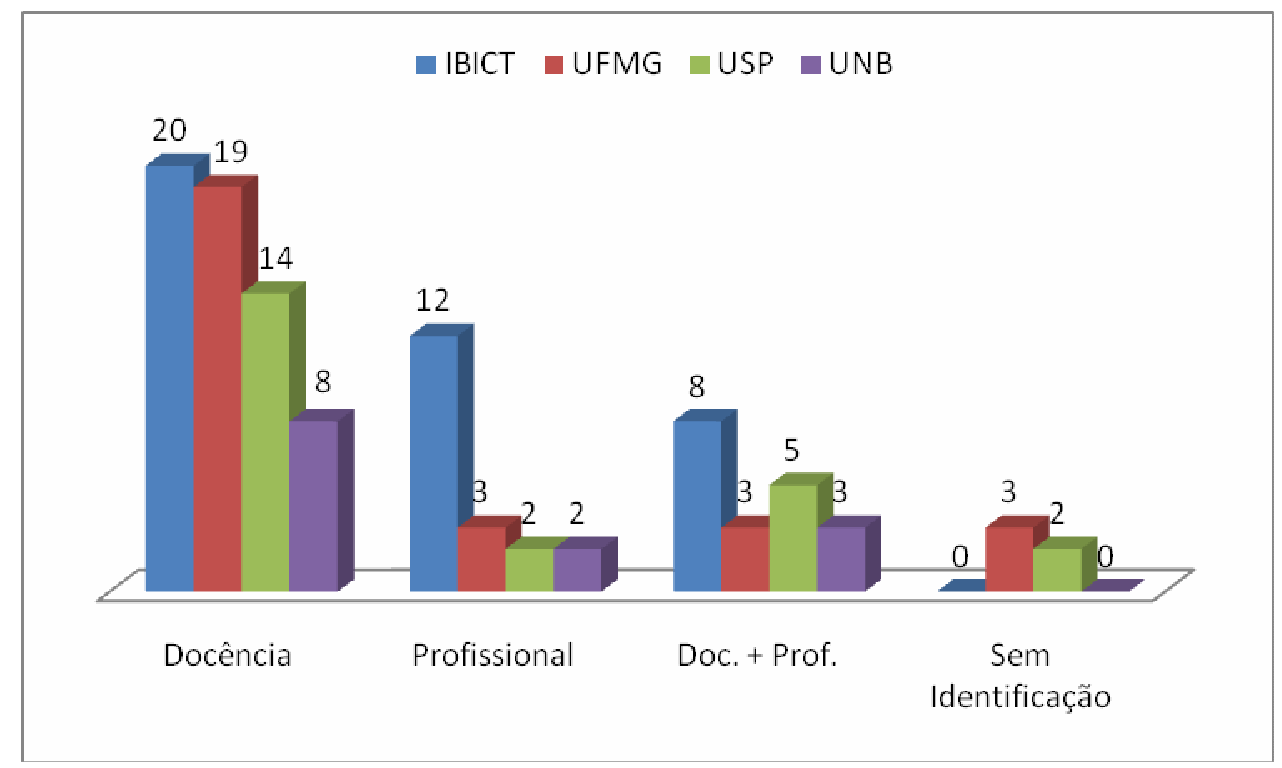

GRÁFICO 2 - Vínculos de atuação dos egressos DEPOIS do doutorado

Fonte: Dados da pesquisa.

\subsection{Atuação na docência após o doutorado}

Os 80 doutores egressos dos PPGsCI (2000-2005) que se dedicaram ao ensino ocupam diversos postos de atuação na docência, envolvendo tanto cursos de graduação, como de especialização e de pós-graduação.

A TAB. 4 mostra a distribuição dos egressos doutores de todos os PPGsCI que atuam, em maior ou menor escala, em todos os níveis da docência. Do total envolvido na docência, 27 dedicam-se exclusivamente à 
graduação, 5 somente à pós-graduação, e apenas um docente se dedica exclusivamente a cursos de especialização. Os demais (47) acumulam atividades de docência nos diferentes níveis: na graduação junto com a pós-graduação (31), na graduação e na especialização (7), na graduação, na pós-graduação e na especialização (7), e na pós-graduação e especialização (2).

Assim, os cursos de graduação detêm a maioria (72) dos egressos, sendo o maior número deles proveniente do programa do IBICT (24), seguido da USP (19), UFMG (18) e UnB (11). Os doutores titulados pelo IBICT e pela USP são os que mais se dedicam ao ensino em nível de pósgraduação; e na especialização o maior número de doutores envolvidos é proveniente do IBICT e da UFMG.

TABELA 4 Atuações na docência após a titulação do doutorado nos PPGsCI (2000-2005)

\begin{tabular}{|c|c|c|c|c|c|}
\hline Atuação na Docência & 1 USP & IBICT & UnB & UFMG & Total \\
\hline Graduação & 3 & 8 & 6 & 10 & 27 \\
\hline Pós-Graduação & - & 2 & - & 3 & 5 \\
\hline Especialização & - & 1 & - & - & 1 \\
\hline Grad. + Pós Grad & 14 & 10 & 4 & 3 & 31 \\
\hline Grad + Esp & - & 1 & 1 & 5 & 7 \\
\hline Grad + Pós Grad + Esp & 2 & 5 & - & - & 7 \\
\hline Pos Grad + Esp & - & 1 & - & 1 & 2 \\
\hline $\begin{array}{ll}\text { TOTAL } \\
\end{array}$ & 19 & 28 & 11 & 22 & 80 \\
\hline
\end{tabular}

Fonte: Dados da pesquisa.

Os diferentes cursos em que atuam os egressos são provenientes de 66 instituições públicas e 32 privadas. Os docentes dos cursos de instituições públicas têm como obrigatoriedade a titulação de doutor para acesso à carreira docente; por isso a maior representatividade em instituições governamentais. Por outro lado, o baixo número de atuação na docência em instituições particulares pode estar relacionado à inexistência dessa obrigatoriedade de titulação para acesso e progressão na carreira docente. Ocorre também que o professor titulado no doutorado muitas vezes é preterido na composição do quadro docente nas instituições privadas, por causa das diferenças salariais de acordo com a titulação. Este também é o quadro verificado na atuação profissional do egresso doutor que, em maior número, está vinculado a instituições públicas.

As FIG. 1 a 4 mostram, para cada Programa analisado, o número de egressos de 2000-2005 que atuam como docentes nos PgsCI.

Dos 104 doutores egressos em 2000-2005, 45 (43,3\%) estão envolvidos em cursos de pós-graduação de instituições públicas e privadas. Desses egressos, $20(19,2 \%)$ dedicam-se às atividades docentes dos 9 programas da área da Ciência da Informação (Mestrado e Doutorado e/ou Mestrado), na época, conforme é mostrado nas FIG. 1 a 4. 
Egressos dos Programas de Pós-Graduação em Ciência da Informação: por onde andam os doutores?
Daisy Pires Noronha, Dinah Aguiar Población, Leonardo da Silva de Assis, Tatiana Hyodo

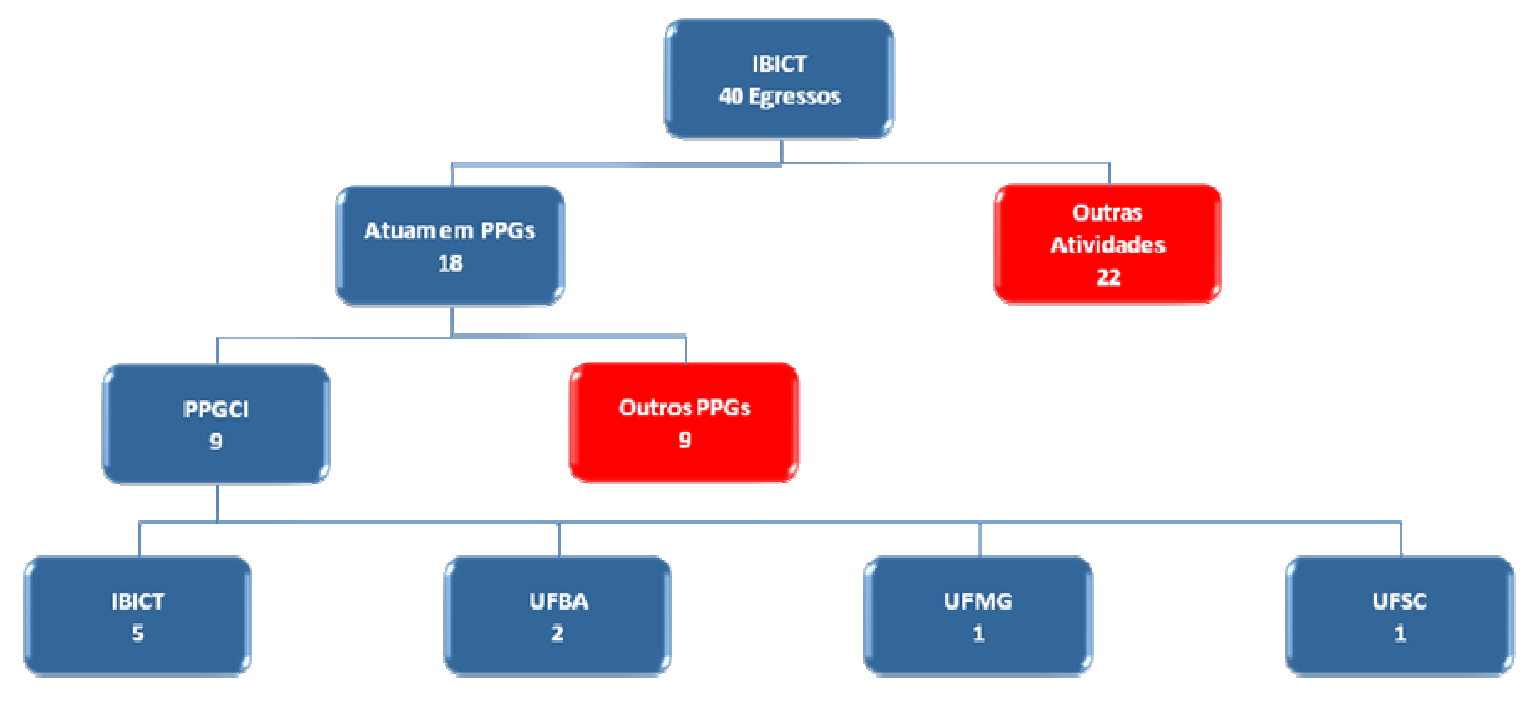

FIGURA 1 - Doutores egressos do IBICT (2000-2005) que atuam nos diversos PPGsCl

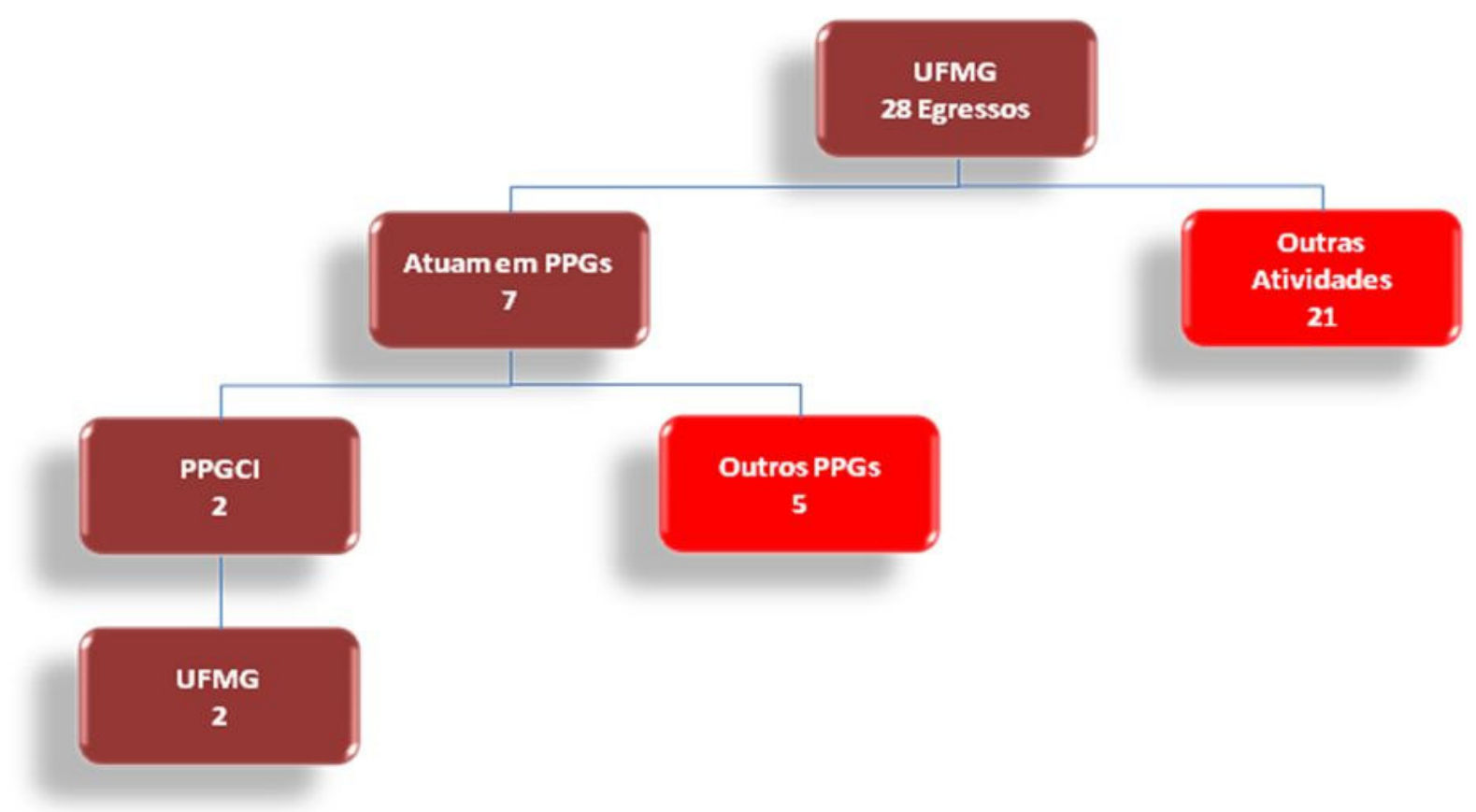

FIGURA 2 - Doutores egressos da UFMG (2000-2005) que atuam nos diversos PPGsCI 


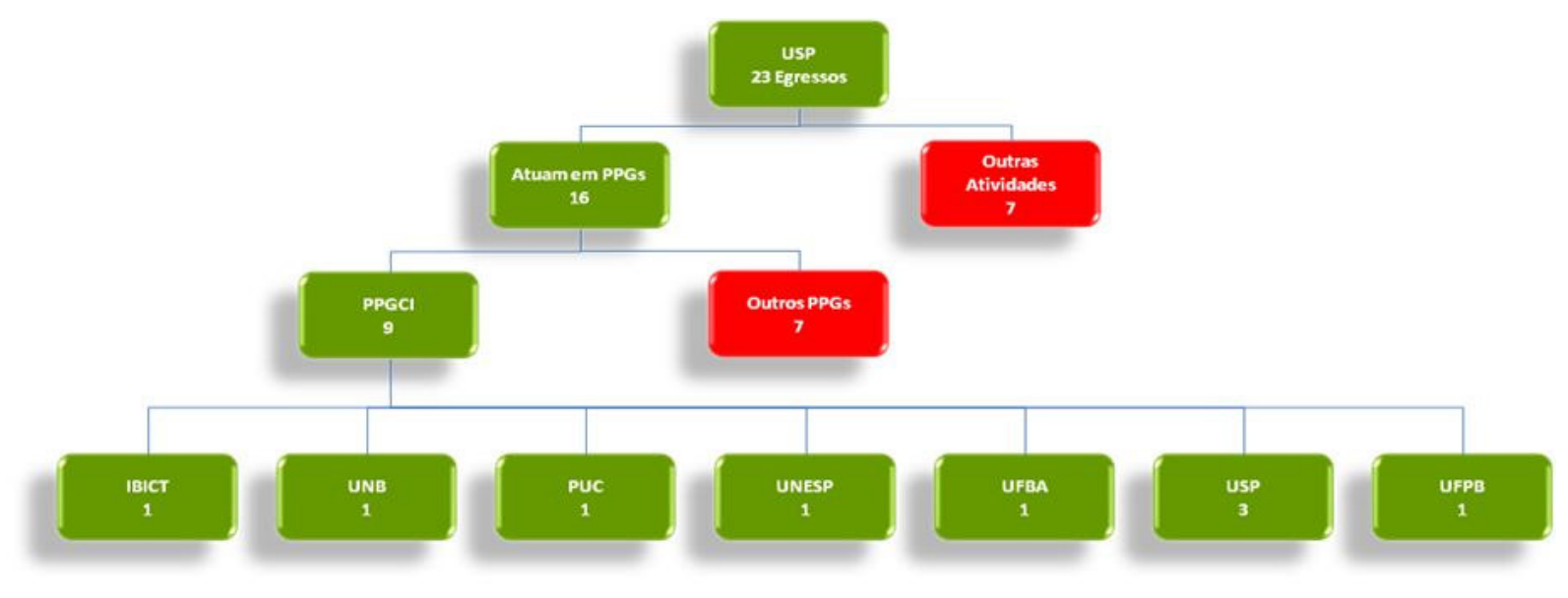

FIGURA 3 - Doutores egressos do USP (2000-2005) que atuam nos diversos PPGsCI

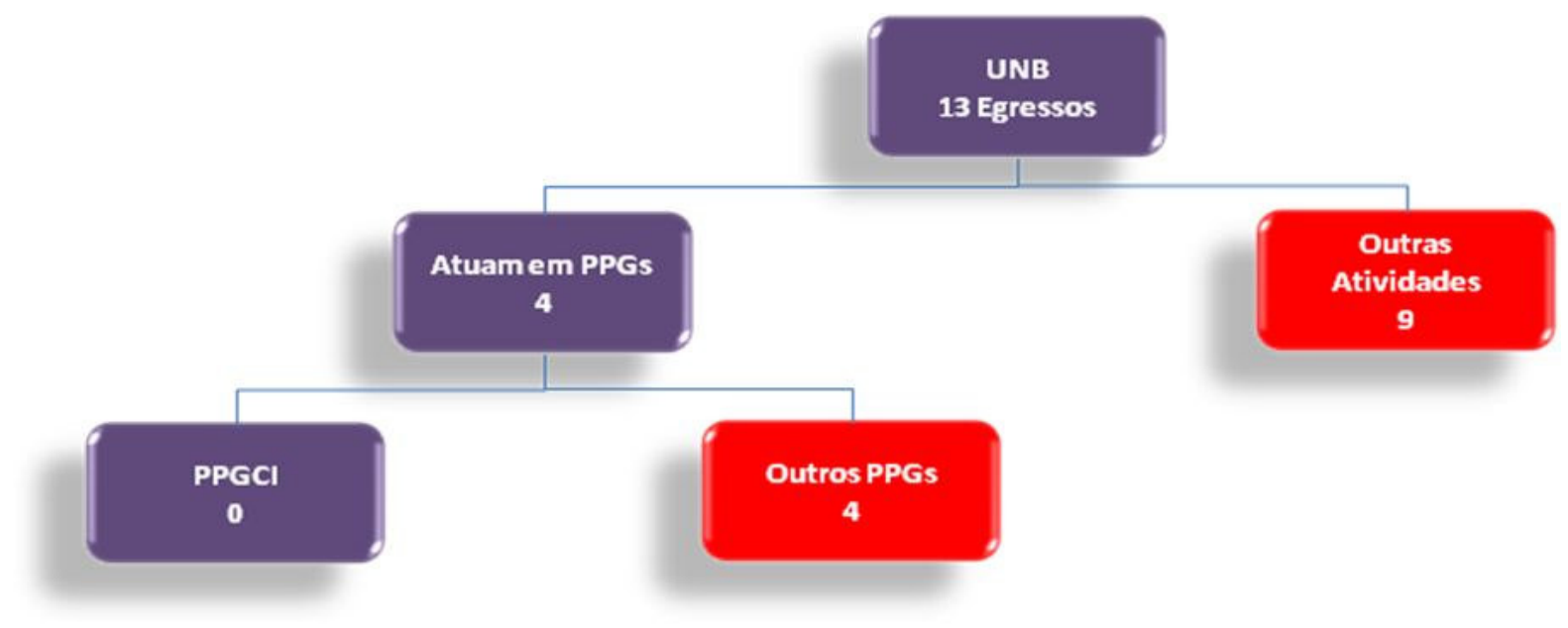

FIGURA 4 - Atuação dos doutores egressos da UnB nos diversos PPGsCI

Assim, dos 9 titulados pelo IBICT (FIG. 1) envolvidos na docência, 5 fazem parte do corpo docente desse Programa; 2 atuam na UFBA e 1 na UFMG e na UFSC. O PPGCI da USP (FIG. 3) contribuiu com 9 doutores atuando em 7 dos 9 programas (USP, UFBA, UFPB, IBICT, UNESP, PUCCAMP e UnB, sendo 3 na própria USP) - apenas os programas da UFSC e UFMG não contaram com os egressos doutores da USP desse período. Os 2 doutores que cursaram no PPGCI da UFMG atuam no mesmo programa como docentes (FIG. 2). Nenhum doutor egresso da UnB, no período, atua nos PPGs CI (FIG. 4).

A complementação desses dados é mostrada na Figura 5, que ilustra, mediante localização geográfica dos PPGsCI, a distribuição do número de egressos/doutores que atuam nesses Programas após a titulação obtida no período do estudo. 


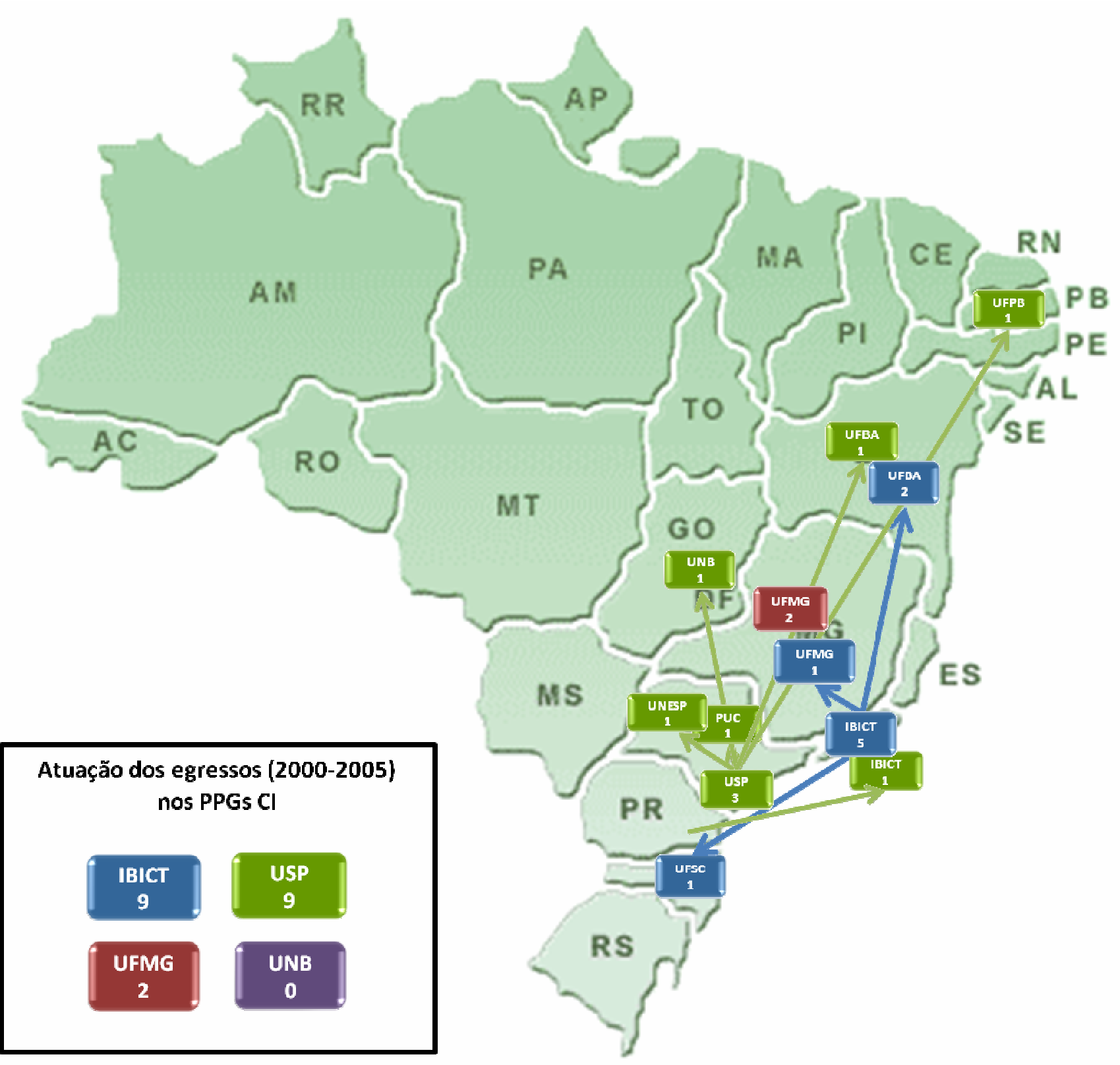

FIGURA 5 - Distribuição dos egressos doutores nos PPGsCI

Quanto à formação profissional dos 20 egressos doutores envolvidos nos PPGs CI, a maior parte é constituída por bibliotecários/ documentalistas (8). Os demais são provenientes das áreas das ciências sociais, ciência da computação, história, letras, jornalismo, medicina e engenharia. Desses, 3 possuem graduação em duas áreas. Não foi possível identificar a área de sua graduação de 3 dos egressos. 


\section{Considerações finais}

Ao longo dos 30 anos da institucionalização dos programas de pósgraduação em CI no Brasil, tem-se constatado uma diversificação das áreas de formação daqueles que demandam esses cursos para sua titulação no doutorado. Além disso, o perfil da comunidade docente mostra que essa área, absorvendo ensinamentos que servem para todos, encontra-se em pleno desenvolvimento na delimitação de sua esfera de atuação. O fato dos PPGsCI arrolarem em seu quadro docentes com experiências "extra-muros" é mais um fator para enriquecer o aperfeiçoamento de seus alunos. A interdisciplinaridade da CI torna-se cada vez mais clara com esse quadro.

O presente estudo mostra parte de um cenário, os 6 primeiros anos do século 21, onde se constata que os PPGsCI cumprem o principal objetivo da pós-graduação no preparo da comunidade acadêmica, com o crescente envolvimento dos doutores no ensino da graduação, em cursos de especialização e, principalmente, nos programas de pós-graduação. Com isso, além de contribuir na formação de massa crítica da área, propicia a constituição de um campo vasto e diversificado para a especulação científica de temas de interesse a profissionais de diferentes áreas.

\section{Referências}

BARRETO, A. A. Pensando a pós-graduação em informação no Brasil. In: SEMINÁRIO NACIONAL DOS CURSOS DE PÓS-GRADUAÇÃO EM CIÊNCIA DA INFORMAÇÃO E BIBLIOTECONOMIA, 12., 1992, São Paulo. Anais... São Paulo: [s.n.], 1993.

GUIMARÃES, R. Pesquisa no Brasil: a reforma tardia. São Paulo em Perspectiva, v. 16, n. 4, out./dez. 2002. Disponível em: <www.scielo.br>. Acesso em: 01 ago. 2007.

MIRANDA, A. Pesquisa científica em ciência da informação [editorial]. Ciência da Informação, Brasília, v. 27, n. 1, p. 5-6, 1998.

MUELLER, S. P. M.; MIRANDA, A.; SUAIDEN, E. O estado da arte da pesquisa em ciência da informação no Brasil: análise dos trabalhos apresentados no IV Enancib, Brasília, 2000. In: ENCONTRO NACIONAL DE PESQUISA EM CIÊNCIA DA INFORMAÇÃO (EnANCIB), 4., 2000. Anais... Brasilia, DF: ANCIB, 2000.

NORONHA, D. P.; FUJINO, A. Teses e dissertações em ciência da informação: a multidisciplinaridade não revelada na avaliação da produção científica. In: ENCONTRO NACIONAL (EnANCIB), 7., 2006, Marília, SP. Anais... Marilia: ANCIB, 2006. CD-ROM.

POBLACIÓN, D. A. Pesquisa e pós-graduação em Ciência da Informação e Biblioteconomia no Brasil: duas fases (1970/1985-1986/1992). In: ENCONTRO NACIONAL DE PESQUISA EM CIÊNCIA DA INFORMAÇÃO 
(EnANCIB), 12., 1992, São Paulo. Anais... São Paulo: ANCIB/CNPq/ECAUSP, 1993. p. 11-23.

POBLACIÓN, D. A.; NORONHA, D. P. Rumos da comunidade brasileira de pesquisadores em Ciência da Informação: desafios do século XXI. In: ENCONTRO NACIONAL DE PESQUISA EM CIÊNCIA DA INFORMAÇÃO EnANCIB, 5., 2003, Belo Horizonte. Anais. Belo Horizonte: ANCIB, 2003. CD-ROM.

POBLACION, D. A.; PRAZERES, A. P. P.; OLIVEIRA, L. C. Evolução dos de pesquisa em ciência da informação no diretório do CNPq. In: SEMINÁRIO NACIONAL DE BIBLIOTECAS UNIVERSITÁRIAS, 14., 2006, Salvador, BA. Anais... Salvador, 2006. CD-ROM.

SANTOS, J. S. Atuação profissional e participação no desenvolvimento do campo científico em Ciência da Informação: estudos dos egressos do Programa de Pós-Graduação em Ciência da Informação da UFMG, 19922005. 270f. Dissertação (Mestrado em Ciência da Informação) - Escola de Ciência da Informação, Universidade Federal de Minas Gerais, Belo Horizonte, 2006.

SAVIANI, D. Os fundamentos da educação e a nova LDB. Revista Educação Municipal, v. 1, n. 3, p. 5-17, 1988 citado por POBLACIÓN, D. A. Pesquisa e pós-graduação em Ciência da Informação e Biblioteconomia no Brasil: duas fases (1970/1985-1986/1992). In: ENCONTRO NACIONAL DE PESQUISA EM CIÊNCIA DA INFORMAÇÃO (EnANCIB), 12., 1992, São Paulo. Anais... São Paulo: ANCIB/CNPq/ECA-USP, 1993. p. 11-23.

VELLOSO, J. (Coord.) A pós-graduação no Brasil: formação e trabalho de mestres e doutores no país. Cadernos de Pesquisa, v. 4, n. 122, p. 517, maio/ago. 2004. 